\begin{tabular}{c} 
International Journal of Engineering \& Technology, $7(4.5)(2018) 552-555$ \\
SPC \\
Website $\frac{w w w . s c i e n c e p u b c o . c o m / i n d e x . p h p / I J E T}{\text { Research paper }}$ \\
\hline
\end{tabular}

\title{
Estimation of properties of mixed waste cooking oil for production of biodiesel
}

\author{
B. S. V. S. R. Krishna ${ }^{1}$, Shivaraj B. $\mathbf{K}^{1}$ \\ ${ }^{1}$ Professor, Department of Chemical Engineering \\ ${ }^{2}$ M Tech, Chemical Engineering MIT, MAHE, MANIPAL-576104 \\ *Corresponding author E-mail: krishna.bandaru@manipal.edu
}

\begin{abstract}
The major drawback of production of biodiesel in large scale is the cost of raw materials. Raw material source of biodiesel is mostly plant oil (Jatropha, Pongamia, Mahua, Neem, Cotton seed oil etc.) which requires large land area to grow. One of the best methods to reduce the production cost of biodiesel is to employ low quality feedstock, for instance waste cooking oil (WCO). This also solves the disposal problem of WCO. This is socioeconomic and environment friendly, it does not compete with edible oil resources. This study represents the biodiesel production from mixed waste cooking oil. Waste cooking oil collected from different hotels around Manipal, Udupi district of Karnataka State, and India. Collected WCO from various sources (from palm oil and sunflower oil users) have different physical and chemical properties. These WCO has mixed in different ratios ie. 50:50, 75:25 and 25:75 to reduce free fatty acid content of WCO without any chemical pre-treatment. Physio-chemical properties of mixed WCO has been carried out.
\end{abstract}

Keywords: Waste Cooking Oil (WCO); Free Fatty Acid (FFA); Low Quality Feed Stock; Biodiesel.

\section{Introduction}

Raising uncertainty about global energy production and supply, environmental concerns due to the use of fossil fuels and the high \& uncertain price of petroleum based products are the main rea-sons for invention of alternatives to petroleum based products. The global supply of oil and natural gas from the conventional sources is improbable to meet the growth in energy demand over the next 25 years [1]. One of the main driving force for biodiesel widespread is the emission of greenhouse gases ( $\mathrm{CO} 2$ being the major one). The use of waste cooking oil as biodiesel feedstock reduces the cost of biodiesel production since the feedstock costs constitutes approximately 70-95\% of the overall cost of biodiesel production [2], [3]. Hence, the use of waste cooking oils and non-edible oils should be given higher priority over the edible oils as biodiesel feedstock to protect the food safety.

Moreover, biodiesel fuel has become more attractive because of its environmental benefits, due to the fact that plants and vegetable oils and animal fats are renewable biomass sources [1]. Biodiesel represents a largely closed carbon dioxide cycle (approximately 78\%), as it is derived from renewable biomass sources. Compared to petroleum diesel, biodiesel has lower emission of pollutants; it is biodegradable, nontoxic, has carbon neutrality, it enhances the engine lubricity and contributes to sustainability [4-5]. Biodiesel has a higher cetane number than diesel, and no aromatics, no sulfur; secondly, it contains $10-11 \%$ oxygen by weight [2].

According to ASTM D6751, biodiesel is composed of mono-alkyl esters of long-chain fatty acids derived from plant oils or animal fats. Biodiesel is chiefly made by transesterification of oils or by esterification of free fatty acids with alcohols. Biodiesel is a suitable outlet for the big hotels and restaurants and vegetable oil industry requiring little or no changes in current diesel engines when used in blends and also increases engine life due to its superior lubricity over petrodiesel. Usage of biodiesel will allow a balance to be sought between agriculture, economic development and the environment.

Biodiesel produced from fresh vegetable oils costs much more than diesel, this is a major drawback to the commercialization of biodiesel in the market. Therefore, it is necessary to find the ways to minimize the total production cost of biodiesel. In this context, methods that can reduce the costs of raw materials as well as the energy consumption are of special concern. The use of waste cooking oils (WCO) is one of attractive options to reduce the raw material cost. Moreover, many harmful compounds are produced during the frying of vegetable oils, therefore EU banned the use of waste cooking oils in the composition of animal feed in 2002. Most of the toxic compounds in the waste cooking oil are oxida-tion products from fatty acids, especially from polyunsaturated fatty acids [6], [7].

Chemically the oils/fats consist of triglyceride molecules of three long chain fatty acids that are ester bonded to a single glycerol molecule. Because different fatty acids have different physical and chemical properties, the fatty acid profile is probably the most important parameter influencing the corresponding properties of a vegetable oil or animal fat. Thus, biodiesel refers to lower alkyl esters of long chain fatty acids, which are synthesized either by transesterification with lower alcohols or by esterification of fatty acids. Low-grade oil, typically waste cooking oil can be a better alternative; however, the high free fatty acids (FFA) content in waste cooking oil has become the main drawback for this potential feedstock. Waste cooking oil (WCO) as biodiesel feedstock

Huge quantities of waste cooking oils and animal fats are available across the world, especially in the developed and developing countries. Such oils and fats set a significant challenge because of their disposal problems and possible contamination of the water and land resources. Even though some of this waste cooking oil is used for 
soap production, a major part of WCO's are discharged into the environment. According to a study performed in USA, $40 \%$ of the sewerage system blockages are caused by the waste frying oils poured into kitchen sink [8]. Moreover, waste frying oils have ecotoxic properties. If they are spilled onto ground, they will contaminate the soil and so damage plants. Waste cooking oil, which is otherwise wasted, is one of the most economical choices to produce biodiesel. Since one of the major concerns on biodiesel production is the price of feedstock, utilization of waste cooking oil significantly enhances the economic viability of biodiesel pro-duction. The following table provides the major producers of $\mathrm{WCO}$, which can be converted to biodiesel.

Biodiesel is commonly produced using homogeneous alkaline catalyst, such as sodium hydroxide $(\mathrm{NaOH})$ or potassium hydrox-ide $(\mathrm{KOH})$. These catalysts are very commonly used in the indus-tries due to following reasons: (i) Operates at low reaction temper-ature and atmospheric pressure; (ii) High conversion can be achieved in a minimal time, (iii) Widely available and more eco-nomical (Lotero et al., 2005) [9]. In fact, it was reported that the transesterification reaction rate for base-catalyzed reaction would be 4000 times faster compared to acidic catalyst (Fukuda et al., 2001 [9], Kulkarni and Dalai, 2006 [7].

Table 1: Quantity of Waste Cooking Oil Produced In Selected Countries (Gui Et Al. 2008) [11]

\begin{tabular}{ll}
\hline Country & Quantity (million tonnes/year) \\
\hline India & 9.2 \\
China & 4.5 \\
European & $0.7-1.0$ \\
Canada & 0.12 \\
Taiwan & 0.07 \\
United States & 10.0 \\
Malaysia & 0.5 \\
Japan & $0.45-0.57$ \\
\hline
\end{tabular}

\section{Literature survey}

Freedman and Pryde (1982) [12] investigated the effects of reaction variables on transesterification using sunflower and soybean oils. They studied different molar ratios of alcohol to oil, alcohol types, catalyst types, and reaction temperature. In that study, ester conversions of 90 to $97 \%$ were obtained by using alcohol to oil molar ratios of 4:1 and 6:1, respectively, with an alkaline catalyst. They have used two catalysts (sodium hydroxide and sodium methoxide) at 6:1 and 3:1 molar ratios and found that sodium methoxide $(0.5 \%)$ was more effective than sodium hydroxide $(1 \%)$ at the $3: 1$ molar ratio. At the 6:1 molar ratio, the catalysts were equally effective. Muniyappa et al. [13] studied transesterification yield of soybean oil. Sodium hydroxide was used as a catalyst and its effect was investigated by changing its concentration from 0.5 to $0.05 \%$ in a $30: 1$ molar ratio of methanol to soybean oil. All reactions were run at about $68-70^{\circ} \mathrm{C}$, with a 90 -minute reaction time, and with soy-bean oil having an acid value less than $0.05 \mathrm{mg} \mathrm{KOH} / \mathrm{g}$. They found that $98 \%$ conversion could be obtained with $0.1 \%$ catalyst after only 5 10 minutes of reaction time.

The primary parameters relevant to biodiesel production by transesterification of WCO by alcohol using a base catalyst are the FFA content and moisture content. The FFA content of WCO will vary and depends on the quality of the feed stock. Another tech-nique to increase the biodiesel yield is acid catalyst based esterifi-cation; however, it is much slower than the alkali catalyst based transesterification.

Freedman and co-workers (1984) [14] compared the transesterification of crude and refined cottonseed, peanut, soybean, and sunflower oils. They noted that the free fatty acid level is higher in crude vegetable oils than in refined oils. The ester conversions decreased from $95 \%$ to $67 \%, 98 \%$ to $83 \%, 93 \%$ to $84 \%, 97 \%$ to $81 \%$, for peanut, soybean, cottonseed, and sunflower oil, respec-tively, when crude oils were used. In that research, it was stressed that the yields of ester were reduced significantly when the acid value was higher than $1 \mathrm{mg} \mathrm{KOH} / \mathrm{g}$.
Freedman and Pryde (1982) [12] reported that the oil should not contain more than $1 \%$ FFA for alkaline-catalyzed transesterification reactions. If the FFA level exceeds this amount, the formation of soap will inhibit the separation of the ester from the glycerin and also reduce the ester conversion rate.

FFA content in oil feedstock should be as low as possible (ranging from less than 0.5 wt. \% to less than 2 wt. \%) for base-catalyzed transesterification reaction. Thus, if waste cooking oil with an average FFA content more than $6 \mathrm{wt}$. \%, base catalyst is definitely not suitable to be used (Lotero et al., 2005) [9]. If FFA of waste cooking oil is more than $1 \mathrm{wt} \%$, then it should be treated prior to transesterification reaction to reduce FFA level less than $1 \mathrm{wt} \%$. So many methods are available to reduce FFA value including acid catalyzed reaction, two step acid-base catalyzed reaction, acid esterification, esterification with methanol, esterification with glycerol and utilization of acid heterogeneous catalysts, utilization of adsorbents to reduce FFA. All these methods require high cost and energy requirement. This leads to the increase in production of biodiesel. Best method to reduce the FFA of WCO is mixing of high FFA value WCO with low FFA value oil in different ratios. This method significantly reduces the FFA of oil, without using any chemicals. The main objective of this study was characterisation of waste cooking oil and mixed waste cooking oil, reduction of FFAs of collected waste cooking oil without any chemical treatment, just by mixing the waste cooking oil in different ratios for biodiesel production.

\section{Experimental}

\subsection{Materials}

Different waste cooking oils were obtained from the various ho-tels around Manipal, Udupi district, India. A total of $10 \mathrm{~kg}$ of waste cooking oil was collected for the optimization of the bio-diesel production process. The oil collected in two containers, specific preference is given for collection process such way that in container one for sunflower oil and container two for palm oil.

\subsection{Pre-treatment of waste cooking oil}

The frying process often introduces food particles to the oil, and the oil must be filtered before undergoing the transesterification reaction. The collected waste cooking oil was filtered through normal sieve to remove food debris and unwanted solids. In addi-tion to food particles, foods introduce water to the fryer oil. It was heated to around $100{ }^{\circ} \mathrm{C}$ to evaporate the possible water content present in oil. The pretreated waste cooking oil was named as sample no 01 and 05

\subsection{Mixing of waste cooking oil}

Treated waste cooking oils were mixed in 50:50, 75:25 and 25:75 ratios.

a) $500 \mathrm{ml}$ of sample 01 (sunflower oil) and $500 \mathrm{ml}$ of sample 02 (palm oil) taken in a beaker, stirred it at $600 \mathrm{rpm}$ and temperature was maintained at $85{ }^{\circ} \mathrm{C}$ to mix properly and named it as sample 03 .

b) $750 \mathrm{ml}$ of sample 01 (sunflower oil) and $250 \mathrm{ml}$ of sam-ple 02 (palm oil) taken in a beaker, stirred it at 600RPM and temperature was maintained at $85^{\circ} \mathrm{C}$ to mix properly and named it as sample 04

c) $250 \mathrm{ml}$ of sample 01 (sunflower oil) and $750 \mathrm{ml}$ of sample 02 (palm oil) taken in a beaker, stirred it at 600RPM and temperature was maintained at $70^{\circ} \mathrm{C}$ to mix properly and named it as sample 05 .

\subsection{Characterization of waste cooking oil}

The quality of oil is expressed in terms of the physiochemical properties such as moisture, acid value, saponification value, io-dine 
value, unsaponified matter, peroxide value, density, specific gravity, viscosity. All physiochemical properties of the waste cooking oil were conducted according to the standard AOCS methods [15].

\subsection{Transesterification reaction procedure}

A laboratory scale reactor in the form of a $2000 \mathrm{ml}$ three-neck round bottom flask equipped with a reflux condenser was used for the transesterification reactions. Out of three necks, in one neck spiral condenser was fixed, in second thermometer was fixed, and other neck was used to put the raw oil inside the reactor as well. The reactor was placed in a heating mantle equipped with a stirrer and temperature controller. The stirrer speed was set at $600 \mathrm{rpm}$.

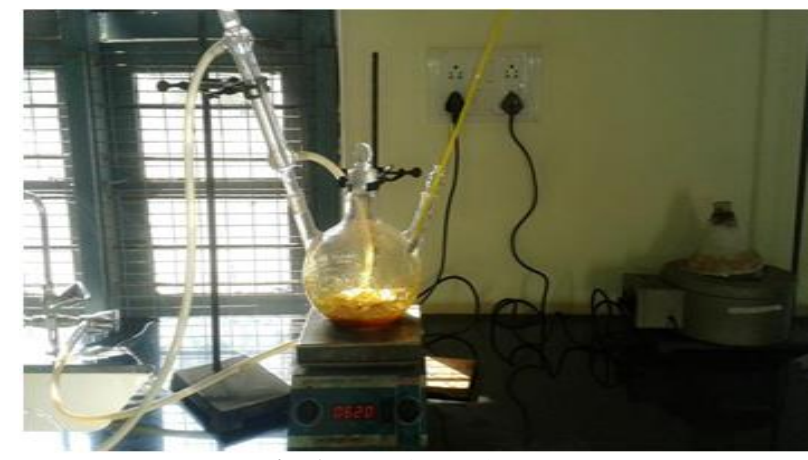

Fig. 1: Experimental Setup.

\section{Results and discussion}

\subsection{Characterization of waste cooking oil}

The following Physio-chemical properties of mixed oil were characterized.

i) Moisture content

ii) Specific gravity

iii) Viscosity

iv) Acid value and free fatty acid content

v) Saponification value

vi) Iodine value

vii) Peroxide value

viii) Unsaponifiable matter

The variation of Moisture content with sample is presented in Fig 2. The moisture content in sample 4 is comparatively less than other samples. Similarly the Acid value of the waste mixed cook-ing oil, FFA and Unsaponification values are presented in Figs 3 to 5. One can observe that the sample 4 shows relatively low acid value, low FFA and low saponification relatively with other mixed cooking oils. The Physiochemical properties of waste mixed cook-ing oil samples along with waste cooking oils are presented in Table 2.

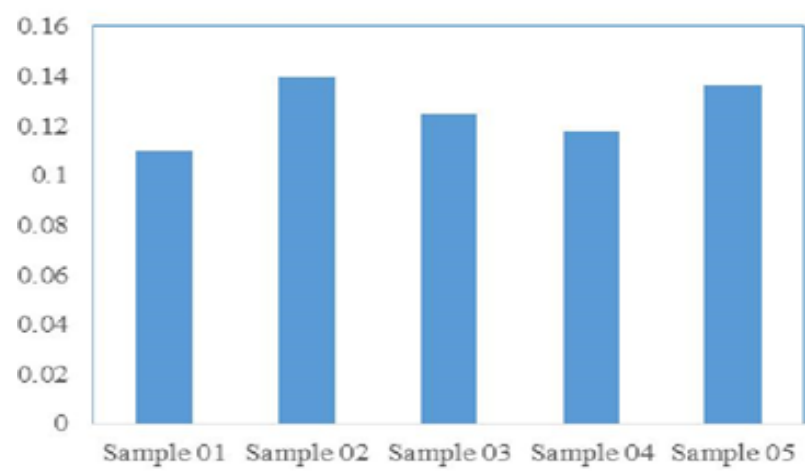

Fig. 2: Variation of Moisture with Samples.

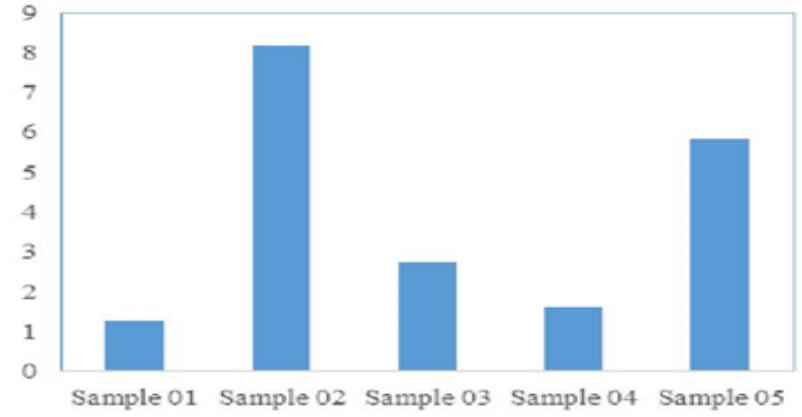

Fig. 3: Variation of Acid Value with Sample.

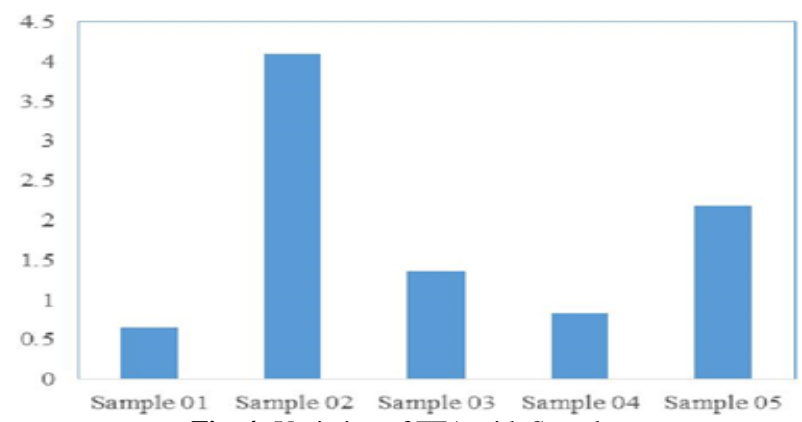

Fig. 4: Variation of FFA with Sample.

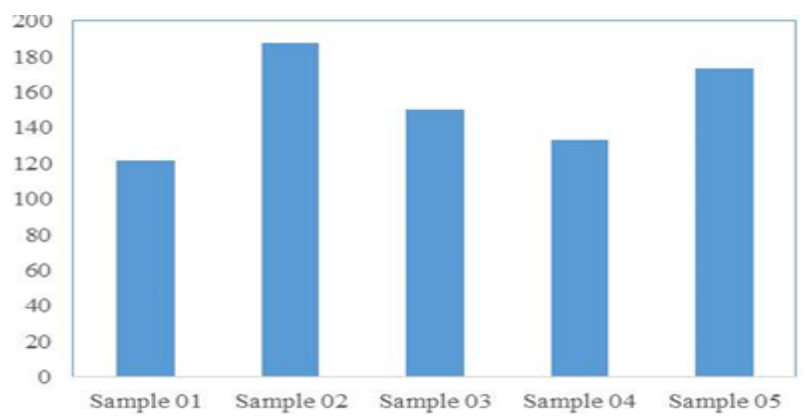

Fig. 5: Variation of Saponification Value with Samples.

Table 2: Physiochemical Properties of Waste Cooking Oil Samples Oil samples name/ sample

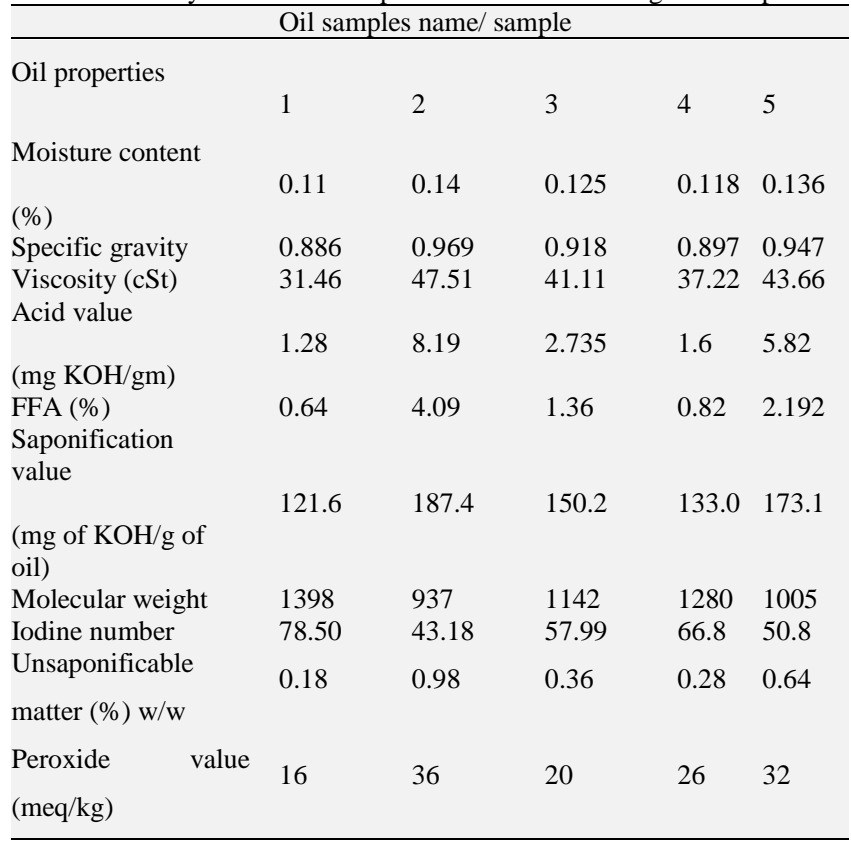

From the table 2 the FFA\% is more with sample 2 while the sample 1 and 5 are very close to FFA of $1 \%$, which is desirable for experimentation. Sample 1 is raw WCO while Sample 5 is mixed MCO, present research was selected sample 5 of MCO [16].

\subsection{Preparation of biodiesel}


50 gm of waste cooking oil sample 05 has taken in three necks round bottom flask and pre-heated oil at $60^{\circ} \mathrm{C}$. Calculated amount of $\mathrm{KOH}$ and known quantity of methanol taken in conical flask. Heated the mixture to prepare methanolic $\mathrm{KOH}$ and added to the treated WCO in a round bottom three necked. Started the reaction, set the required $\mathrm{rpm}$ and allowed it for required time at required temperature. After completion of the reaction, reacted mixture was allowed to cool. Next, the mixture was transferred to a separating funnel and allowed to settle at room temperature; the mixture separated into three layers. The upper layer, which was biodiesel and bottom layer mostly, contains glycerol, salts, soap, other impuri-ties and excess methanol. Both layers separated and biodiesel was heated to evaporate methanol residual. In next step it was washed with hot distilled water to remove residual catalyst or soaps and other impurities until clear. Again heated the biodiesel to remove any water molecules present in biodiesel, to get pure moisture free biodiesel. Washed and dried moisture free biodiesel stored in air tight bottle.

Biodiesel yield was calculated using following equation (1)

$\%$ Biodiesel yield $=\frac{\text { Weight of fatty acid methyl estres }}{\text { Weight of oil taken }} \times 100$

The influence of catalyst concentration on biodiesel production is shown in Figure 5. The catalyst concentration varied from 0.4 to 1.5 wt \% [13] and kept the other three parameters constant: oil to methanol ratio $(1: 6)$, temperature $\left(65^{\circ} \mathrm{C}\right)$ and time (60 minutes). The yield of biodiesel increased initially and reaches maximum, further increase in catalyst concentration reduced the yield. A threshold level of $0.4 \mathrm{wt} \% \mathrm{KOH}$ loading observed for biodiesel production, it's mainly because of added catalyst may not be suf-ficient to driven the reaction forward. Biodiesel yield was reached a maximum of $90.40 \%$ at $0.85 \mathrm{wt} \%$ potassium hydroxide, this may be increased amount of catalyst loading increased the interactive sites of the catalyst; thus, reaction was accelerated and biodiesel yield was increased. However, the yield was reduced to $83.52 \%$ with further increase in catalyst. This may be more soap for-mation, which prevented the separation of the biodiesel layer dur-ing the washing step. The soap particles formed emulsions with water. As a consequence, the yield of biodiesel was reduced be-yond the catalyst loading of $1.0 \mathrm{wt} \%$. The optimum loading of potassium hydroxide in this study was approximately close to the literature. This was mainly because of presence of lower FFAs present in the waste cooking oil samples. More FFAs present in oil demands an addition of potassium hydroxide to balance for this acidity.

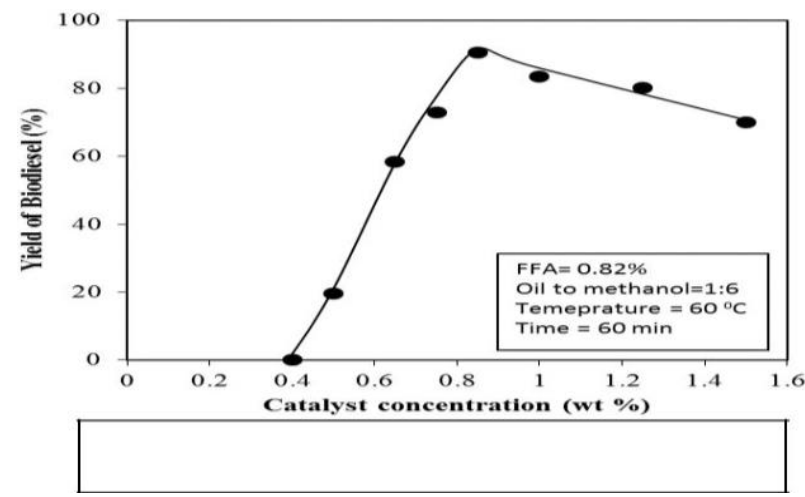

Fig. 6: Influence of Catalyst Concentration on Biodiesel Production.

\section{Results and discussion}

The waste cooking oils are good raw materials for biodiesel production as this can solve dual problems of disposal of waste cooking oils into water bodies and otherwise reduces the raw material cost of the biodiesel. The collected raw materials properties analysed and presented to choose the suitable mixed cooking oil for the production of biodiesel. Sample 4 shows better results in terms of physiochemical properties and yield of biodiesel.

\section{Acknowledgements}

The authors would like to thank the KSCST for the financial support extended.

\section{References}

[1] Tan K.T., Lee K.T \& Mohamed A.R., "Potential of waste palm cooking oil for catalyst-free biodiesel production", Energy 36 (2011) 2085-2088.

[2] Cvengros J. \& Z. Cvengrosova, "Used frying oils and fats and their utilization in the production of methyl esters of higher fatty acids", Biomass Bioenergy 27 (2004) 173-181.

[3] Chhetri, A.B., K. Chris Watts \& M. R. Islam, "Waste cook-ing oil as an alternate feedstock for biodiesel production", Energies 2008, 1, 2008, pp. 3-18.

[4] Maddikeri G.L., Pandit A.B. \& Gogate P.R., "Intensifica-tion approaches for biodiesel synthesis from waste cooking oil: a review", Ind. Eng. Chem. Res. 51 (45) (2012) 14610- 14628.

[5] Gopal K.N., Pal A., Sharma S., Samanchi C., Sathyana-rayanan K. \& Elango T., "Investigation of emission and combustion characteristics of a CI engine fueled with waste cooking oil methyl ester and diesel blends", Alexandria Eng. J. 53 (2014) 281-287.

[6] Encinar J. E., Gonzalez J. F. \&A. R. Reinares, "Biodiesel from used frying oil. Variables affecting the yields and characteristics of the biodiesel," Ind. Eng. Chem. Res, vol. 44, pp. 5491-5499, June 2005.

[7] Kulkarni M. G. and Dalai A. K., "Waste cooking oil an economical source for biodiesel: A review," Industrial and Engineering Chemistry Research, vol. 45, pp. 2901-2913, March 2006.

[8] Agriculture and Food Development Authority, Waste Oils and Fats as Biodiesel Feedstocks: An Assessment of Their Potential in the EU, ALTENER Program NTBNETT Phase IV, Task 4, Final Report, March 2000.

[9] Lotero E., Liu Y, Lopez D.E, Suwannakarn K, Bruce D.A \& Goodwin Jr JG. "Synthesis of biodiesel via acid catalysis". Ind Eng Chem Res 2005; 44:5353-63.

[10] Fukuda, H., Kondo, A. \& Noda, H.’Biodiesel fuel pro-duction by transesterification of oils". Journal of Bioscience and Bioengineering 92(5):405- 416. 2001.

[11] Gui M.M., Lee K.T. \& Bhatia S. "Use of edible oil vs. non-edible oil vs. waste edible oil as biodiesel feedstock", Energy 2008; 33:164653.

[12] Freedman, B., \& Pryde E. H., "Fatty Esters from Vege-table Oils for Use as a Diesel Fuel," Vegetable Oil Fuels - Proceeding of the International Conference on Plant and Vegetable Oils as Fuels, pp.117, ASAE Publication 4-82, Fargo, ND, 1982.

[13] Muniyappa, P. R., Brammer S. C. \& Noureddini H., "Improved Conversion of Plant Oils and Animal Fats into Biodiesel and Co-product," Bioresource Technology, Vol. 56, pp. 19, 1996.

[14] Freedman, B., Pryde E. H., \& Mounts T. L., "Variables Affecting the Yields of Fatty Esters from Transesterified Vegetable Oils," JAOCS, Vol. 61, No. 10, pp. 1638, 1984.

[15] Lab manual 2, Manual of methods of analysis of foods - Oils and Fats, Food safety and standards authority of India ministry of health and family welfare government of India, NewDelhi 2012.

[16] Szmigielski M, "Evaluation of chosen quality parame-ters of used frying rape oil as fuel biocomponent," Int. Ag-rophys, vol. 22, no. 4, pp. 361-364, 2008. 